\title{
LINEAR ELECTRIC MOTOR FOR HANDHELD ELECTRIFIED TOOLS USED IN GARDENING
}

\author{
Sergey Antonov, Gennady Nikitenko \\ Stavropol State Agrarian University, Russia \\ antonov_serg@mail.ru, nikitenko_gv@mail.ru
}

\begin{abstract}
In gardening, a large amount of work is done in crown care and harvesting. Automated harvesting gains special significance due to uneven ripening of fruits and berries. Electrification of these works contributes to increasing the productivity and reducing production costs. One of the methods of automated harvesting of fruits and berries is vibratory. To create vibrations, the use of a linear electric motor is recommended. The presented electric motor can be used for harvesting devices and for manual electrified pruners and delimbers. Analysis of the existing linear electric motors made it possible to identify their shortcomings. The main disadvantage is the low thrust of the armature and expensive technology in the manufacture. The work of the proposed electric motor is based on the use of magnetic flux scattering. These magnetic fluxes appear as a result of magnetic saturation of sections of the magnetic system. The design of the magnetic system of the stator of the motor is alternating sections of large and small thickness in the ratio of $1 / 3$. The magnetic flux passing through a section of the magnetic system of small thickness is ejected toward the armature and magnetizing the coil due to magnetic saturation. The armature of the electric motor is made in the form of alternating magnetic and nonmagnetic rings. The displaced magnetic flux from the magnetic system of the stator passes through the magnetic ring of the armature. As a result, a force acts on the armature, forcing it to move. The main task in modeling a linear electric motor is to rationalize the design of the magnetic system. It is necessary to obtain the maximum redistribution of the magnetic flux towards the armature. This will increase the armature thrust and efficiency. The studied parameters of the magnetic system are the angle of inclination of the poles and the length of narrowing of the magnetic circuit. The results of the study show that the maximum value of the thrust force $F_{a}=59.32 \mathrm{~N}$ is obtained at $\alpha=90^{\circ}$ and $l=10 \mathrm{~mm}$.
\end{abstract}

Keywords: magnetic flux, magnetic saturation, linear electric motor, traction force, pruner, delimber.

\section{Introduction}

In horticulture, harvesting and pruning of branches is one of the most responsible and intensive farming seasons. Labor costs for fruits and berries collection as well as pruning of branches can reach $60 \%$ of all annual labor inputs. The following requirements are imposed on harvesting: removal of fruits and berries with minimal losses, preservation of commercial quality, rapid realization of perishable fruits and berries, timely laying for storage or processing. Pruning of branches has special requirements for the cut smoothness.

The main requirement for harvesting machines is to ensure $95 \%$ of shaking down and catching fruits and berries. Hydraulic and pneumatic systems are used to create vibratory movements. The main disadvantage of these systems is inability to smoothly regulate the force and frequency of vibrations. These parameters have a significant impact on tree crown damage $[1 ; 2]$.

Analysis of the existing harvesting devices in horticulture allowed us to identify the following equipment groups: hand (Fig. 1, a), semi-mechanized (SP-0.5, MAJA, etc.) (Fig. 1, b), mechanized (combines - Lisicki, VST, Joanna, Victor, etc. (Fig. 2, b); fruit harvesting machines - berry harvester МПЯ-1, berry electric harvester ЭЯМ-200-8, fruit harvester BCO-25, hydraulic tower AC2, etc. (Fig. 2, a)).

a)

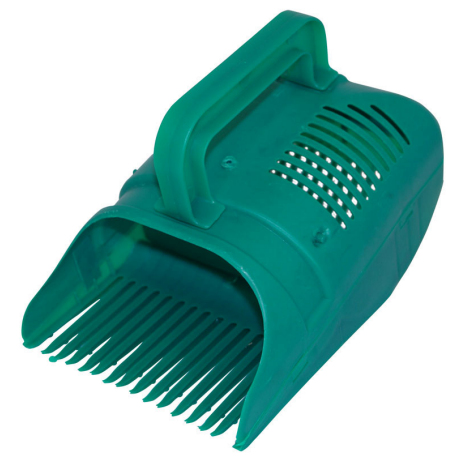

b)

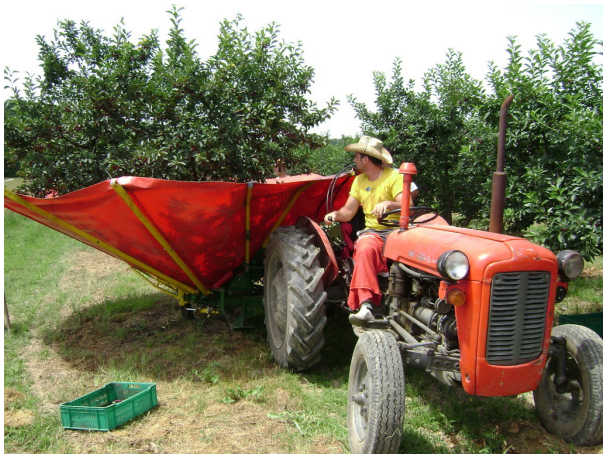

Fig. 1. Equipment for harvesting fruits and berries: $a$ - hand; $b$ - semi-mechanized 
a)

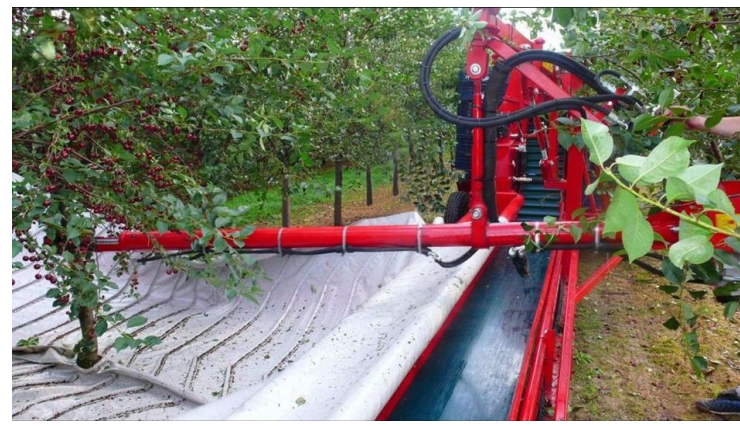

b)

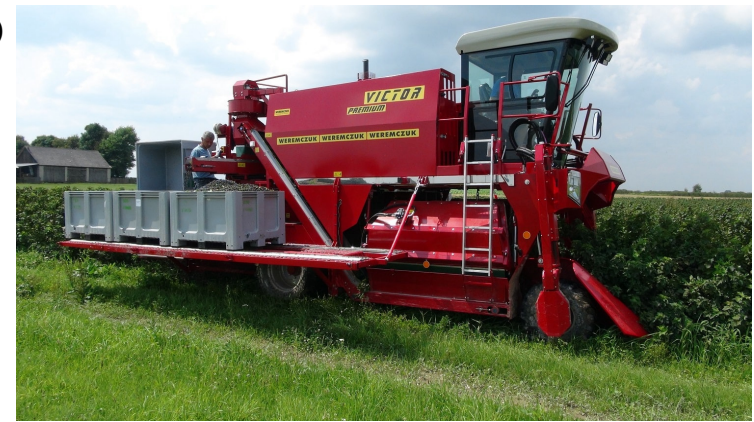

Fig. 2. Mechanized harvesting of fruits and berries:

$a$ - machine harvesting; $b$ - fruit harvesting combine

The considered harvesting machines and combines are used in farms engaged in the industrial production of fruit and berry crops. The use of this machinery in small or private subsidiary farms is not profitable. It is recommended to use mobile vibrating devices for harvesting in small farms in order to increase labor productivity. The analysis of the existing means of small-scale mechanization for harvesting in horticulture has led to use of shakers, based on an asynchronous electric motor with various kinematic schemes. The main disadvantages of these structures are mass and dimensional indicators, as well as the presence of an industrial or high-frequency power supply [3;4].

The analysis of the existing electrified pruners is given in the articles [5-7].

\section{Materials and methods}

For development of an electrified tool in horticulture, a linear electric motor is proposed that generates vibrational oscillations. It consists (Fig. 3.) of a stator (1), which comprises a magnetic body (2), magnetizing coil (3), non-magnetic frame (4), magnetic circuit (5), bolts (6), end magnetic circuit (7), armature (8) of a linear electric motor consists of an upper magnetic bushing (9), middle magnetic bushing (10), lower magnetic bushing (11), upper non-magnetic ring (12), lower non-magnetic ring (13) mounted on a non-magnetic rod (14). In the stator (1), the armature (8) is installed using nonmagnetic bearings (15) and (16). Return spring (17) fixed with the washer (18) and nut (19) is used to return the armature (8) to the starting position.

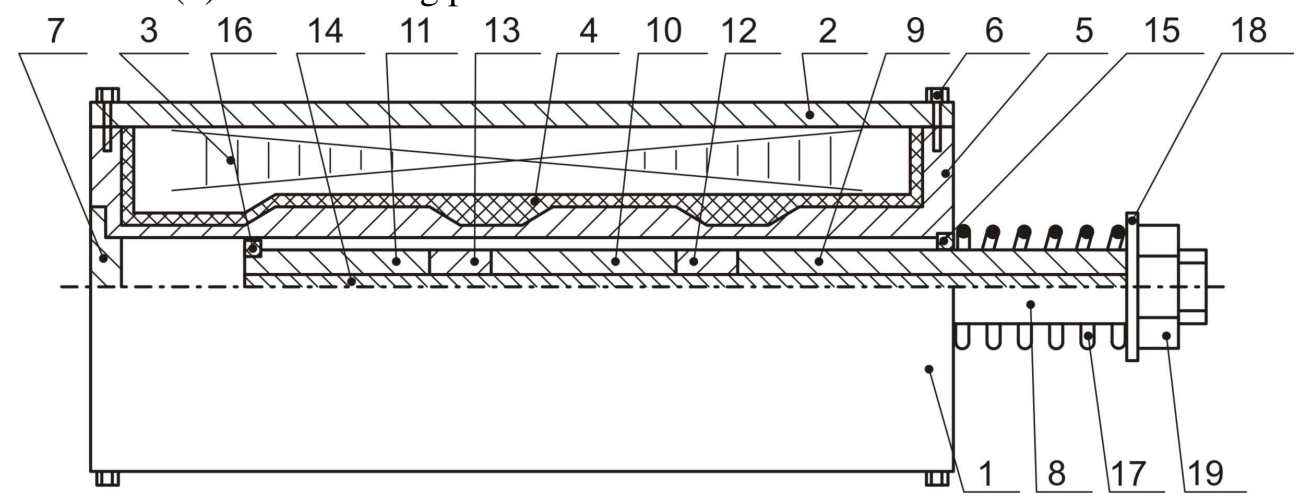

Fig. 3. Linear motor: 1 - stator; 2 - magnetic body; 3 - magnetizing coil; 4 - non-magnetic frame;

5 - magnetic circuit; 6 - bolt; 7 - end magnetic circuit; 8 - armature; 9 - upper magnetic sleeve;

10 - average magnetic sleeve; 11 - lower magnetic sleeve; 12 - upper non-magnetic ring;

13 - lower non-magnetic ring; 14 - non-magnetic rod; 15 - non-magnetic bearing; 16 - non-magnetic bearing; 17 - return spring; 18 - washer; 19 - nut

The linear electric motor works as follows (Fig. 4.): in the power supply absence of the magnetizing coil (3), the armature (8) occupies the extreme right position under the action of the return spring (17). When voltage $(24 \mathrm{~V})$ is applied to the magnetizing coil (3), the current $(1 \ldots 2 \mathrm{~A})$ begins to flow throught it and creates magnetic flux $\Phi$. The magnetic flux $\Phi$ closes the magnetic body (2) and the magnetic circuit (5).

At the constriction points of the magnetic circuit (5), the magnetic flux $\Phi$ is divided into magnetic fluxes $\Phi_{1 \mathrm{w}}-\Phi_{1 \mathrm{~s}}-\Phi_{1 \delta}, \Phi_{2 \mathrm{w}}-\Phi_{2 \mathrm{~s}}-\Phi_{2 \delta}, \Phi_{3 \mathrm{w}}-\Phi_{3 \mathrm{~s}}$. Separation of the magnetic flux $F$ is possible at the 
constriction points due to the magnetic saturation of the area and the ejection of the magnetic fluxes $\Phi_{1 \mathrm{w}}-\Phi_{1 \delta}, \Phi_{2 \mathrm{w}}-\Phi_{2 \delta}, \Phi_{3 \mathrm{w}}$. As a result of the magnetic fluxes $\Phi_{1 \mathrm{w}}, \Phi_{2 \mathrm{w}}, \Phi_{3 \mathrm{w}}$, an electromagnetic force appears, which leads to the armature (8) displacement.

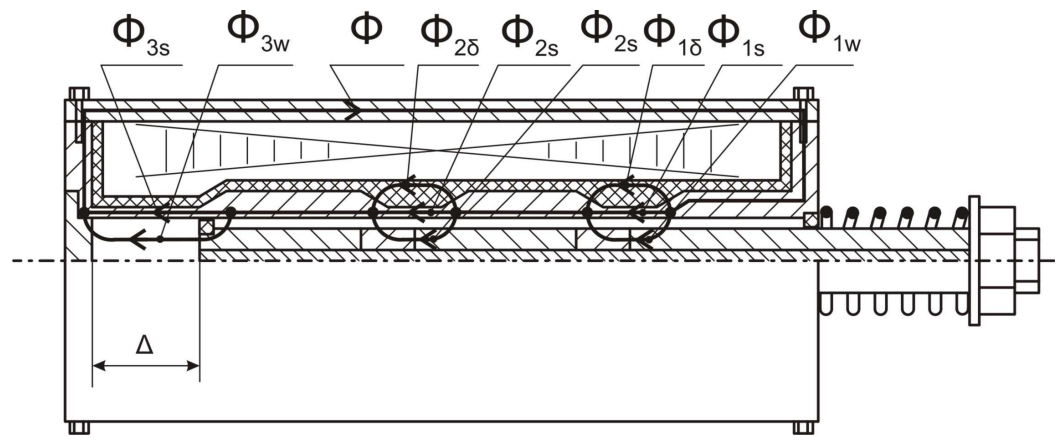

Fig. 4. Magnetic fluxes of linear electric motor

\section{Results and discussion}

At the initial stage of design rationalization of the magnetic system, it is necessary to obtain the maximum values of the armature thrust force. This is primarily due to the cutting force of the branches and the force, with which the vibrating device will act on the quality of shaking down fruits and berries.

The task of modeling a linear electric motor is reduced to the definition of a rational design of the magnetic system. The main parameters that cause emergence of electromagnetic force, which drives the armature, are the working magnetic fluxes $\Phi_{1 \mathrm{w}}, \Phi_{2 \mathrm{w}}$ and $\Phi_{3 \mathrm{w}}$. Therefore, when modeling a magnetic system, it is necessary to obtain the maximum redistribution of the magnetic fluxes $\Phi_{1 s}, \Phi_{1 \delta}$, $\Phi_{2 \mathrm{~s}}, \Phi_{2 \delta}$ and $\Phi_{3 \mathrm{~s}}$ in the direction of the magnetic fluxes $\Phi_{1 \mathrm{w}}, \Phi_{2 \mathrm{w}}$ and $\Phi_{3 \mathrm{w}}$. To this end, let us single out a number of factors affecting the magnetic fluxes redistribution (Fig. 5.): 1. The constriction point thickness of the magnetic circuit $(a) ; 2$. The thickness of the magnetic circuit $(b) ; 3$. The constriction length of the magnetic circuit (1); 4 . The inclination angle of the magnetic circuit thickenings $(\alpha)$.

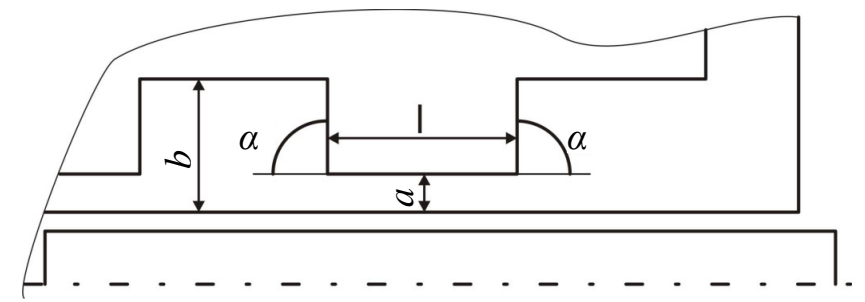

Fig. 5. Factors for modeling magnetic system of linear motor

To model the magnetic system of an electric motor, we use the professional version of the ELCUT program. As a result of the calculation, we obtain a picture of the magnetic fluxes distribution (Fig.6.)

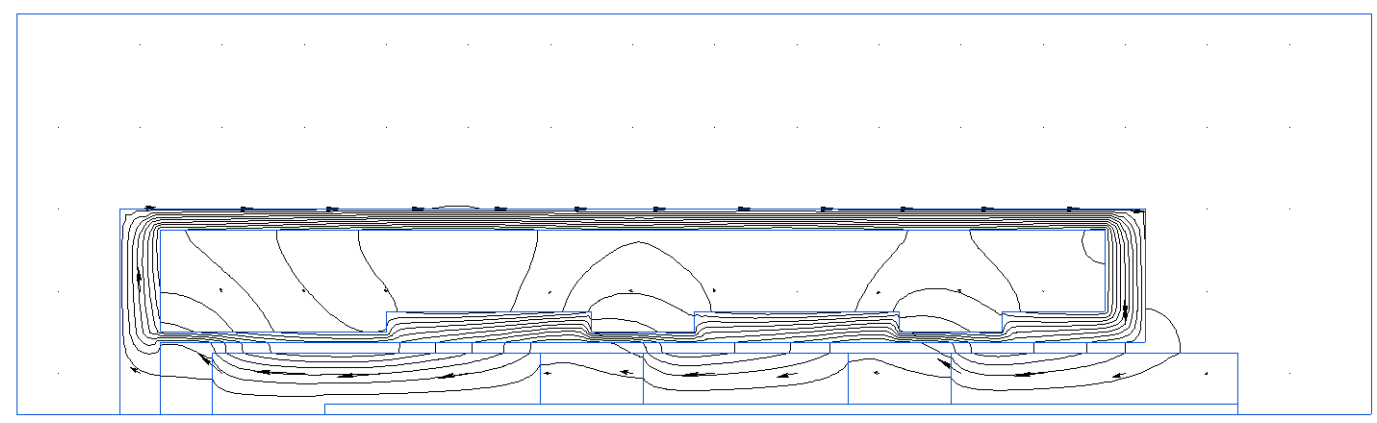

Fig. 6. Calculation result of magnetic system of linear motor program ELCUT

Analyzing the pattern of magnetic fluxes distribution, it is necessary to note the separation of magnetic fluxes at the constriction points of the magnetic circuit, which occurs due to the magnetic saturation of this area. 
Table 1 presents the results of the magnetic system modeling with a change in the inclination angle of the magnetic circuit thickenings $(\alpha)$ from $10^{\circ}$ to $90^{\circ}$ at a pitch of $10^{\circ}$ when $l=10 \mathrm{~mm}$, the maximum thrust force $F_{a}=59.32 \mathrm{~N}$ was obtained for $\alpha=90^{\circ}$.

Armature thrust force $\left(F_{a}\right)$ of linear motor, $\mathbf{N}$

Table 1

\begin{tabular}{|c|c|c|c|c|c|c|c|c|}
\hline \multicolumn{8}{|c|}{ Inclination angle of magnetic circuit thickenings $(\boldsymbol{\alpha})$} \\
\hline $\mathbf{1 0}^{\mathbf{0}}$ & $\mathbf{2 0}^{\mathbf{o}}$ & $\mathbf{3 0}^{\mathbf{0}}$ & $\mathbf{4 0}^{\mathbf{o}}$ & $\mathbf{5 0}^{\mathbf{o}}$ & $\mathbf{6 0}^{\mathbf{o}}$ & $\mathbf{7 0}^{\mathbf{o}}$ & $\mathbf{8 0}^{\mathbf{o}}$ & $\mathbf{9 0}^{\mathbf{0}}$ \\
\hline 49.83 & 50.36 & 51.02 & 51.97 & 52.76 & 53.20 & 54.49 & 57.36 & 59.32 \\
\hline
\end{tabular}

Table 2 presents the modeling results of the magnetic system with a change in the thickness ratio of the constriction point of the magnetic circuit (a) to the magnetic circuit thickening $(b)$.

Table 2

Calculation result of armature thrust force $\left(F_{a}\right)$ of linear electric motor, $\mathbf{N}$

\begin{tabular}{|c|c|c|c|c|}
\hline \multirow{2}{*}{$\begin{array}{c}\text { Thickness of the } \\
\text { magnetic circuit } \\
\text { constriction }(\boldsymbol{a}), \mathbf{m m}\end{array}$} & \multicolumn{4}{|c|}{ Thickness of the magnetic circuit thickening } \\
\cline { 2 - 5 }$(\boldsymbol{b}) \mathbf{~ m m}$
\end{tabular}

Considering the data obtained, it should be noted that the armature thrust force reaches the maximum value, when the ratio $a / b=1 / 3$ and $F_{a}=59.32 \mathrm{~N}$.

\section{Conclusions}

The developed linear electric motor can be used to collect fruits and berries, as well as for pruning of branches.

The proposed design of the electric motor was modeled in the program ELCUT. As a result of the magnetic system rationalization of the electric motor, the armature thrust force $F_{a}=59.32 \mathrm{~N}$ reaches the maximum value, when the thickness ratio of the magnetic circuit $a / b=1 / 3$, the inclination angle of the magnetic circuit thickening $\alpha=90^{\circ}$ and the constriction length of the magnetic circuit $l=10 \mathrm{~mm}$.

\section{References}

[1] Антонов С.Н., Никитенко Г.В., Авдеева В.Н., Каланчук И.В., Атанов Г.В. Секатор с линейным электродвигателем (Linear motor pruner). Rural mechanic - 2018, №4, pp. 8-9. (In Russian)

[2] Hedrick U.P. Cyclopedia of Hardy Fruits. New York: The MacMillan Company, 1922. 370 p.

[3] Csanády E., Magoss E. Mechanics of Wood Machining. 2-nd ed. Springer-Verlag Berlin Heidelberg, 2013. 199 p.

[4] Antonov S., Nikitenko G., Grinchenko V., Molchanov A., Avdeeva V. Electromechanical secateurs based on a linear electric motor and determination of the cutting force of branches of fruit trees. Ingineering for rural development, Jelgava Latvia, 2018, pp. 514-518.

[5] Ряшенцев Н.П., Ковалев Ю.З. Динамика электромагнитных импульсных систем (Dynamics of electromagnetic pulse systems) - Novosibirsk: Science, 1974, 188 p. (In Russian)

[6] Туриев О.И. Разработка и обоснование основных параметров обрезчика ветвей для крестьянских (фермерских) хозяйств (Development and justification of the main parameters of the cutter branches for peasant (farm) farms): diss. cand. tech. sciences. Vladikavkaz, 1999. $162 \mathrm{p}$. (In Russian)

[7] Усанов К.М. Совершенствование технических средств и технологий АПК системами с электромагнитными импульсными машинами (Improvement of technical means and technologies of the agro-industrial complex with systems of electromagnetic pulse machines): diss. doct. tech. sciences. Saratov, 2008. 433 p. (In Russian) 